\title{
The Incidence of Social Security Contributions in the United Kingdom: Evidence from Discontinuities at Contribution Ceilings
}

\author{
Stuart Adam ${ }^{1}$ - Barra Roantree ${ }^{1,2}{ }_{(D)} \cdot$ \\ David Phillips ${ }^{1}$ (D)
}

Published online: 5 April 2017

(C) The Author(s) 2017. This article is an open access publication

\begin{abstract}
This paper investigates the incidence of National Insurance contributions (NICs) in the UK, exploiting the ceiling that applied to employee and employer contributions between 1975 and 1985 and to employee contributions only between 1986 and 2007. Using data from the New Earnings Survey Panel Dataset, a mandatory survey of British employers' payroll records, we show there was no dip in the earnings density at the ceiling in either period, suggesting that the earnings of those near the ceiling were unresponsive to the change in tax rates. The absence of such a dip allows us to test which of labour cost, gross earnings or net earnings are smooth around the threshold. As shown by Alvaredo et al. (De Econ, 2017. doi:10.1007/s10645-017-9294-7), this is informative about the incidence of the change in tax rates at the threshold on those located nearby. We cannot reject the hypothesis that it is gross earnings that are smooth around the threshold, which may reflect a substantive role for statutory incidence in determining economic incidence. However, a lack of statistical power
\end{abstract}

The authors are grateful to Casper van Ewijk for helpful comments on earlier drafts of this paper and to colleagues at DIW Berlin, CPB Netherlands and IPP Paris School of Economics, working with us on the broader project on 'The impact of social security contributions on earnings' of which this paper is a part, for many helpful discussions throughout the course of the project. All errors and omissions are the responsibility of the authors. We gratefully acknowledge funding from the European Research Council (reference ERC-2010-AdG-269440-WSCWTBDS), the ESRC Centre for the Microeconomic Analysis of Public Policy based at the Institute for Fiscal Studies (ES/M010147/1) and ESRC Research Grant ES/K006185/1. The New Earnings Survey Panel Dataset is Crown copyright material and reproduced with the permission of the Controller of HMSO and the Queen's Printer for Scotland. Access to this data (SN 6706 http://dx.doi.org/10.5255/UKDA-SN-6706-6) was provided by the UK Data Service.

\footnotetext{
$凶$ Barra Roantree

barra_r@ifs.org.uk

1 Institute for Fiscal Studies, London, UK

2 University College London, London, UK
} 
means that, while in some cases we can reject the hypotheses that the full economic incidence of NICs are borne by one side of the market, our results taken alone are also consistent with a wide range of less extreme incidence shares.

Keywords Public economics · Tax incidence $\cdot$ Social security contributions

JEL Classification $\mathrm{H} 0 \cdot \mathrm{H} 22 \cdot \mathrm{H} 24$

\section{Introduction}

Social security contributions (SSCs) are a key component of the labour tax wedge faced by workers, with $21.1 \%$ points of the average OECD labour tax wedge of $35.9 \%$ relating to SSCs in 2015. ${ }^{1}$ In the UK, National Insurance contributions (NICs) accounted for $16.7 \%$ points of the overall $30.8 \%$ labour tax wedge for someone with average earnings.

In this paper we investigate the incidence of NICs in the UK, exploiting the ceiling that applied to employee and employer contributions between 1975 and 1985, and to just employee contributions from 1986 to $2007 .^{2}$ These ceilings created downwards kinks in the NICs schedule that should lead to a dip in the density distribution of earnings: the analogue of bunching expected at upward kinks. Saez (2010) showed that the extent of this dip is proportional to the elasticity of taxable earnings locally. We find no such dip at the NICs ceiling — no detectable earnings response to the fall in marginal tax rate-suggesting either that the underlying elasticities are low or that optimising frictions are significant. This allows us to apply the approach proposed by Alvaredo et al. (2017, this volume) to investigate the incidence of NICs, and we find evidence consistent with a substantive role for statutory incidence in determining economic incidence. While in some cases we can reject the hypotheses that the economic incidence of the fall in NICs rates is borne entirely by either employees or employers, a lack of statistical power means our results taken alone are also consistent with a wide range of other possible incidence shares.

Throughout this paper, we use 'incident on employers' as a shorthand to mean 'incident on someone other than the employee whose earnings were subject to the tax'. Of course, the ultimate burden of a tax must always fall on real people, not the businesses or organisations employing them; it may be passed on to the employers' owners, customers and/or suppliers, and thence perhaps more widely via general equilibrium responses. One important possibility is that a tax that is not incident on the employee whose tax rate changes may nevertheless be incident on a broader group of workers: the nature of market responses may be such that (say) a tax increase affecting one small group of employees results not in a large wage reduction for those employees but in a small wage reduction for all employees in the firm, or in an infinitesimal reduction in equilibrium wages in the wider market. All we attempt to discern in this paper is how an individual's wage is affected by the tax rate applied to that individual's earnings; insofar as their net wage is not reduced one-for-one then we refer to the tax

\footnotetext{
1 See https://stats.oecd.org/Index.aspx?DataSetCode=AWCOMP.

2 For simplicity we refer to the threshold as a 'ceiling' even though from April 2003 there was a 1\% employee NICs rate levied on earnings above this threshold.
} 
as being at least partly incident 'on the employer', even though the burden may be felt by a wider group of employees rather than by (say) the employer's shareholders.

The paper proceeds as follows. We first describe our institutional setting and how NICs are levied in the UK. We discuss our data in Sect. 3, before presenting our main results in Sect. 4. Section 5 concludes. An Appendix gives some additional results and sensitivity tests.

\section{Institutions}

Like SSC systems in most countries, NICs in the UK consist of both employer and employee contributions. Contributions are a function of the employee's gross earnings (including employee, but not employer, private pension contributions) and are calculated separately in each pay period (typically a week or month). ${ }^{3}$

Above an exemption threshold, NICs are charged as a percentage of earnings. Prior to October 1985, employee and employer contributions were both capped at a ceiling called the Upper Earnings Limit (UEL). This meant that there was a downward kink at the UEL where the marginal rates of employee and employer NICs both fell to zero. The cap on employer contributions was removed in October 1985, leaving a downward kink at the UEL in the employee contribution schedule only. (From April 2003 onwards the UEL was no longer a complete cap for employee contributions, but the marginal rate above the UEL was only $1 \%$ so the large downward kink remained.) It is these downward kinks in the NICs schedule that we exploit for our estimation, analysing the periods before and after October 1985 separately because of the large structural reform introduced then.

From April 2008 onwards the UEL was reformed to align it with (the weekly equivalent of) the income tax higher-rate threshold. For individuals with earnings spread evenly across the year and no other income, this meant that the overall marginal rate of tax on earnings now rose rather than fell at the UEL, since the rise in the marginal income tax rate was larger than the fall in the marginal NICs rate. However, since both the tax base and the period of assessment are different for income tax and NICs, for many people the UEL and the higher-rate threshold were not perfectly aligned and their overall marginal could rise and then fall, or vice versa, with varying distance in between the two kink points. Because of these complications, we restrict our analysis to the period before April 2008.

Table 1 shows, for each fiscal year (running from 6 April to 5 April) from 1975 to 1976 (the first year of our data) to 2007-2008, the value of the UEL in pounds per week and the marginal rates of employee and employer NICs that applied on either side of the UEL.

The UEL is routinely uprated in line with inflation each year, which implied quite significant nominal increases in the high-inflation era of the late 1970s and early 1980s. Occasionally it has been changed in real terms, such as the above-inflation increases in April 2000 and April 2001.

3 This is in contrast to income tax, for which final liability depends on income over the tax year as a whole. 
Table 1 Upper Earnings Limit (UEL) and national insurance contribution rates over time

\begin{tabular}{|c|c|c|c|c|c|}
\hline \multirow[t]{2}{*}{ Year } & \multirow[t]{2}{*}{ UEL (£ p.w.) } & \multicolumn{2}{|c|}{ Employee rate } & \multicolumn{2}{|c|}{$\underline{\text { Employer rate }}$} \\
\hline & & Below UEL & Above UEL & Below UEL & Above UEL \\
\hline 1975-1976 & $£ 69.00$ & 5.5 & 0 & 8.5 & 0 \\
\hline 1976-1977 & $£ 95.00$ & 5.8 & 0 & 8.75 & 0 \\
\hline 1977-1978 & $£ 105.00$ & 5.8 & 0 & 10.75 & 0 \\
\hline 1978-1979 & $£ 120.00$ & 6.5 & 0 & 12 & 0 \\
\hline 1979-1980 & $£ 135.00$ & 6.5 & 0 & 13.5 & 0 \\
\hline 1980-1981 & $£ 165.00$ & 6.75 & 0 & 13.7 & 0 \\
\hline 1981-1982 & $£ 200.00$ & 7.75 & 0 & 13.7 & 0 \\
\hline 1982-1983 & $£ 220.00$ & 8.75 & 0 & 12.2 & 0 \\
\hline 1983-1984 & $£ 235.00$ & 9 & 0 & 11.95 & 0 \\
\hline 1984-1985 & $£ 250.00$ & 9 & 0 & 11.45 & 0 \\
\hline $1985^{\mathrm{a}}$ & $£ 265.00$ & 9 & 0 & 10.45 & 0 \\
\hline $1985-1986^{\mathrm{b}}$ & $£ 265.00$ & 9 & 0 & 10.45 & 10.45 \\
\hline 1986-1987 & $£ 285.00$ & 9 & 0 & 10.45 & 10.45 \\
\hline 1987-1988 & $£ 295.00$ & 9 & 0 & 10.45 & 10.45 \\
\hline 1988-1989 & $£ 305.00$ & 9 & 0 & 10.45 & 10.45 \\
\hline $1989^{c}$ & $£ 325.00$ & 9 & 0 & 10.45 & 10.45 \\
\hline $1989-1990^{\mathrm{d}}$ & $£ 325.00$ & 9 & 0 & 10.45 & 10.45 \\
\hline 1990-1991 & $£ 350.00$ & 9 & 0 & 10.45 & 10.45 \\
\hline 1991-1992 & $£ 390.00$ & 9 & 0 & 10.4 & 10.4 \\
\hline 1992-1993 & $£ 405.00$ & 9 & 0 & 10.4 & 10.4 \\
\hline 1993-1994 & $£ 420.00$ & 9 & 0 & 10.4 & 10.4 \\
\hline 1994-1995 & $£ 430.00$ & 10 & 0 & 10.2 & 10.2 \\
\hline 1995-1996 & $£ 440.00$ & 10 & 0 & 10.2 & 10.2 \\
\hline 1996-1997 & $£ 455.00$ & 10 & 0 & 10.2 & 10.2 \\
\hline 1997-1998 & $£ 465.00$ & 10 & 0 & 10 & 10 \\
\hline 1998-1999 & $£ 485.00$ & 10 & 0 & 10 & 10 \\
\hline 1999-1900 & $£ 500.00$ & 10 & 0 & 12.2 & 12.2 \\
\hline 2000-1901 & $£ 535.00$ & 10 & 0 & 12.2 & 12.2 \\
\hline 2001-1902 & $£ 575.00$ & 10 & 0 & 11.9 & 11.9 \\
\hline 2002-1903 & $£ 585.00$ & 10 & 0 & 11.8 & 11.8 \\
\hline 2003-1904 & $£ 595.00$ & 11 & 1 & 12.8 & 12.8 \\
\hline 2004-1905 & $£ 610.00$ & 11 & 1 & 12.8 & 12.8 \\
\hline 2005-1906 & $£ 630.00$ & 11 & 1 & 12.8 & 12.8 \\
\hline
\end{tabular}


Table 1 continued

\begin{tabular}{lllllll}
\hline Year & UEL (£ p.w.) & Employee rate & & \multicolumn{2}{l}{ Employer rate } & \\
& & Below UEL & Above UEL & & Below UEL & Above UEL \\
\hline $2006-1907$ & $£ 645.00$ & 11 & 1 & 12.8 & 12.8 \\
$2007-1908$ & $£ 670.00$ & 11 & 1 & 12.8 & 12.8 \\
\hline
\end{tabular}

Rates shown are those paid on additional employee earnings just below and just above the Upper Earnings Limit (UEL), assuming employee is not contracted out of the State Earnings-Related Pension Scheme (SERPS) or State Second Pension (S2P). Rates include the National Insurance Surcharge applied in addition to the main employers' contribution between April 1977 and October 1984

a Rates applied from April to October 1985

b Rates applied from October 1985 to April 1986

c Rates applied from April to October 1989

d Rates applied from October 1989 to April 1990

Source IFS fiscal facts, http://www.ifs.org.uk/tools_and_resources/fiscal_facts/

With the exception of the 1985 reform, year-on-year changes in the marginal NICs rates either side of the UEL have tended to be small, no more than a couple of percentage points. Over the longer term, however, there are clear trends. In the 1975-1985 period, the marginal rate of employee NICs below the UEL — and therefore the size of the kink-rose steadily, while the employer NICs rate rose more rapidly at first but then fell, so that the kink in the employer NICs schedule went from being more than twice that for employees in April 1979 to being only slightly larger than it in April 1985. Since October 1985, however, there has been no kink in the employer NICs schedule at the UEL, and the kink in the employee NICs schedule has barely changed.

National Insurance was originally envisaged as a 'true' social insurance scheme, with a broadly actuarially fair link between contributions paid and benefit entitlements for each individual. Insofar as there is - or, perhaps, is perceived to be-such a link, National Insurance may not have the same disincentive effects as a simple tax on earnings (Summers 1989). Increasing earnings is made less attractive by the NICs that must be paid on the additional earnings, but simultaneously made more attractive by the increased entitlements it generates; the extent to which these offset each other depends on how much individuals value the increased entitlements. However, the link between contributions and benefits at the margin, never in practice as strong as Beveridge had envisaged, had already been significantly weakened by 1975 , and remained weak throughout the period we analyse. Crucially, while contributions were earnings-related, benefits were largely flat-rate (with one significant exception, discussed below). Thus earning more resulted in higher NICs liabilities but little extra benefit entitlement. It was also possible to accrue benefits without paying NICs (since people also accrued entitlements if they were sick, unemployed, had caring responsibilities, etc.) or to pay additional NICs without accruing additional benefits (e.g. if someone had already accrued maximum entitlement). And for many people additional contributory entitlements accrued would be of little value as they would be offset by reduced means-tested benefit entitlements. The link between contributions and benefits at the margin was even weaker in 2015 than in 1975, because of reforms such as the uncapping of employer NICs, a reduction in the number of years of contributions 
required to attain maximum entitlement, and the increase in the exemption threshold for paying NICs above the threshold for accruing entitlements. ${ }^{4}$

For the purposes of our analysis, what matters is how additional earnings and NICs payments, on each side of the UEL, affected the accrual of future benefit entitlements. Earning more than the UEL was never associated with a discontinuous change in benefit entitlements. And for the most part additional earnings did not affect future entitlements at all, either above or below the UEL: entitlement to the basic state pension, for example, depended (broadly speaking) on the number of years in which an individual had earned more than (the annual equivalent of) the Lower Earnings Limit (the NICs exemption threshold, for most of our period) — or been credited with contributions by virtue of their other activities - and additional earnings or NICs payments beyond that made no difference to entitlement.

The one significant exception to this was the State Earnings-Related Pension Scheme, or SERPS (later the State Second Pension), an earnings-related state pension top-up that people could receive in exchange for opting to pay higher NICs rather than paying lower NICs and joining a 'contracted-out' private pension scheme instead. For those who 'contracted in', SERPS accrual was a function of earnings; but while additional earnings up to the UEL increased SERPS entitlement, additional earnings above the UEL did not. To the extent that people understood and valued these SERPS entitlements, this means that the incentive for individuals below the UEL to increase earnings was slightly stronger than the full (contracted-in) employee NICs rate implied, but that the same was not true above the UEL (since additional earnings above the UEL earned no extra benefit) or for employer NICs (since employers received no benefit in return for their contributions). Thus SERPS means that the 'true' kink in the employee NICs schedule was slightly smaller-in absolute terms and relative to the employer NICs kink - than Table 1 might suggest. We emphasise, however, that [this] applies only to one part of the state pension system, not to the basic state pension or other benefits, and is more significant in some periods than others: SERPS was introduced in 1978, and then its generosity massively reduced in the 1980s and 1990s.

This does not affect our estimation: the mechanical effect of NICs, in compressing the earnings distribution to different extents where the tax rate is different, applies whatever future entitlements may or may not accrue by virtue of those NICs payments. But it will have some minor consequences for the interpretation of our results, to which we return in Sect. 4.

\section{Data $^{5}$}

We use data from the New Earnings Survey Panel Dataset (NESPD), a mandatory survey of employers' payroll records collecting data on employees' earnings and basic characteristics for a pay period each April. ${ }^{6}$ The target sample frame of the NESPD is

\footnotetext{
4 For details of contributory benefits, see Hood and Norris Keiller (2016). The decline of the 'contributory principle' is discussed by Adam and Loutzenhiser (2007) and Hood and Oakley (2014), among others.

5 This section draws heavily on the description in Adam et al. (2017). More detail is provided there.

6 The NESPD is in fact the result of joining together the old New Earnings Survey and the similar Annual Survey of Hours and Earnings which replaced it from 2004.
} 
civilian employees in Great Britain whose National Insurance (NI) number ends with a specific pair of digits. Since the last digits of NI numbers are allocated randomly to all adults and the NESPD sample uses same pair of digits each year, in principle this should deliver a random 1\% panel sample of employees. At around 165,000 individuals per year, the NESPD contains a much larger sample than is available in other datasets of hours and earnings (such as the Labour Force Survey and the Family Resources Survey) and does not suffer from the same degree of measurement error, as responses are provided by employers with reference to their payroll and employment records.

In practice, the NESPD is not quite a random $1 \%$ sample of employees. In fact, it includes around $0.7 \%$ of employees on average over the period (1\% of employees in Britain would be around 235,000 per year, not the 165,000 we actually observe). The main reason for this is that, despite supposedly being mandatory, the survey suffers from significant non-response. The valid response rate fell from over $75 \%$ in the $1980 \mathrm{~s}$ to around $60 \%$ by $2012 .^{7}$ Non-response reduces sample size and therefore the precision of our estimates, though as noted above our sample remains large. Non-random nonresponse is unlikely to be an issue for our approach, which relies on identifying a discontinuity at the UEL: response rates would need to differ for those just below and just above the threshold. ${ }^{8}$

The main earnings variable recorded in the NESPD measures total cash earnings (including pay for overtime, shift premiums, commission, performance-related pay, etc.), excluding benefits in kind and employer pension contributions but without deducting employee pension contributions, relating to a particular pay period (typically a week or month, but in all cases converted to a weekly equivalent by the data provider). This corresponds closely to the tax base for NICs, which is levied on a very similar definition of earnings and is charged separately in each pay period. ${ }^{9}$

One feature of the data which complicates our analysis is the proximity of the earnings we observe to the turn of the fiscal year, which runs from 6 April to 5 April. Changes in NICs rates and thresholds usually take effect at the start of the fiscal year. The NESPD collects information each year about earnings and hours of work in the particular pay period that includes the 'survey reference date', a specific date in April. The precise date varies from year to year, ranging from 4 April to 29 April. Hence the earnings level reported by the employer in the NESPD will refer to the pay period containing the survey reference date, but the applicable NICs rate will generally depend on whether the amount in question is paid before or after 6 April.

\footnotetext{
7 Source: authors' correspondence with the Office for National Statistics.

8 There are a number of more minor reasons that our sample may not be completely random, although we do not expect these to have a significant effect on the validity of results.

9 The only difference we are aware of is that some taxable benefits in kind might not be included in the earnings measure reported by employers (see Adam et al. 2017, for details). This would lead us to underestimate taxable earnings (or, for some benefits in kind in the latter half of our data, underestimate taxable earnings for employer NICs purposes but not for employee NICs purposes). Systematic measurement error in earnings is potentially problematic for our methodology, though less so for our preferred polynomial approach than for the alternative McCrary approach described below. But we think the magnitude of any discrepancy is small and unlikely to have a significant impact on our findings: overall we consider the accuracy of earnings reported in our data to be a strength, not a weakness.
} 
Earnings in respect of the pay period containing a particular date in April may be paid before or after 6 April, so we cannot be certain which fiscal year's NICs schedule applies to the earnings in our data, and so what contribution cap applies. For example, if the employee's pay period is the calendar month then the employer will record their April earnings in the survey; but if the employee is paid on the first day of each month then those April earnings will be subject to the NICs schedule for the old fiscal year (ending on 5 April), whereas if they are paid on the 15th day or the last day of each month then their April earnings will be subject to the NICs schedule for the new fiscal year (starting on 6 April). Similar ambiguities can arise for employees with other pay periods, depending on the relationship between the survey reference date, the lengths and dates of pay periods, and the point in the pay period at which earnings are actually paid.

For the large majority of observations in our dataset, the earnings we observe will be subject to the NICs schedule of the fiscal year just beginning, but this will not be the case for all observations (particularly in years when the survey reference date is near the start of April) and we cannot identify those for which it is not true. We therefore test the robustness of our results to the use of the previous year's threshold.

A final complication arises from the tendency for employees to be paid in round number amounts, particularly multiples of $£ 10$ per week or $£ 100$ per year: the 'round number bunching' problem identified by Kleven and Waseem (2013). To avoid conflating a spike in the distribution of earnings at one of these round numbers with a positive discontinuity (which we would interpret as evidence that the incidence of NICs falls on firms), we follow Kleven and Waseem and drop individuals with weekly or annualised earnings that take common integer values.

\section{Results}

A downwards kink in the NICs schedule should lead to a dip in the density distribution of earnings: the analogue of the bunching expected at convex kink points. Saez (2010) showed that the extent of this dip is proportional to the elasticity of earnings locally. We begin by plotting the distribution of gross earnings around the UEL to see whether such a dip is observable. Pooling years of data to reduce noise, Fig. 1a shows the distribution of gross earnings relative to the UEL across the period from 1975 to 1985, when both employee and employer NICs were capped at this threshold, while Fig. 1b shows this across the period from 1986 to 2007, when there was a downwards kink at this threshold in the employee NICs schedule only. Negative values refer to real (April 2015) pounds per week below the threshold and positive values pounds per week above the threshold.

No dip is visible at the threshold (shown by the vertical line at 0 ) in either Figure, indicating that taxable earnings were inelastic with respect to the rate of NICs. ${ }^{10,11}$

\footnotetext{
10 The absence of a dip in the distribution is robust to the choice of bin size, here $£ 1$ per week.

11 Since (as described in Sect. 3) additional earnings below, but not above, the UEL generated extra SERPS or State Second Pension entitlement for much of our period, the lack of a dip in the earnings distribution does not imply a taxable earnings elasticity quite as near zero as it otherwise might, since the disincentive to increase earnings does not decline quite as much at the UEL as it appears from looking at the tax rates
} 

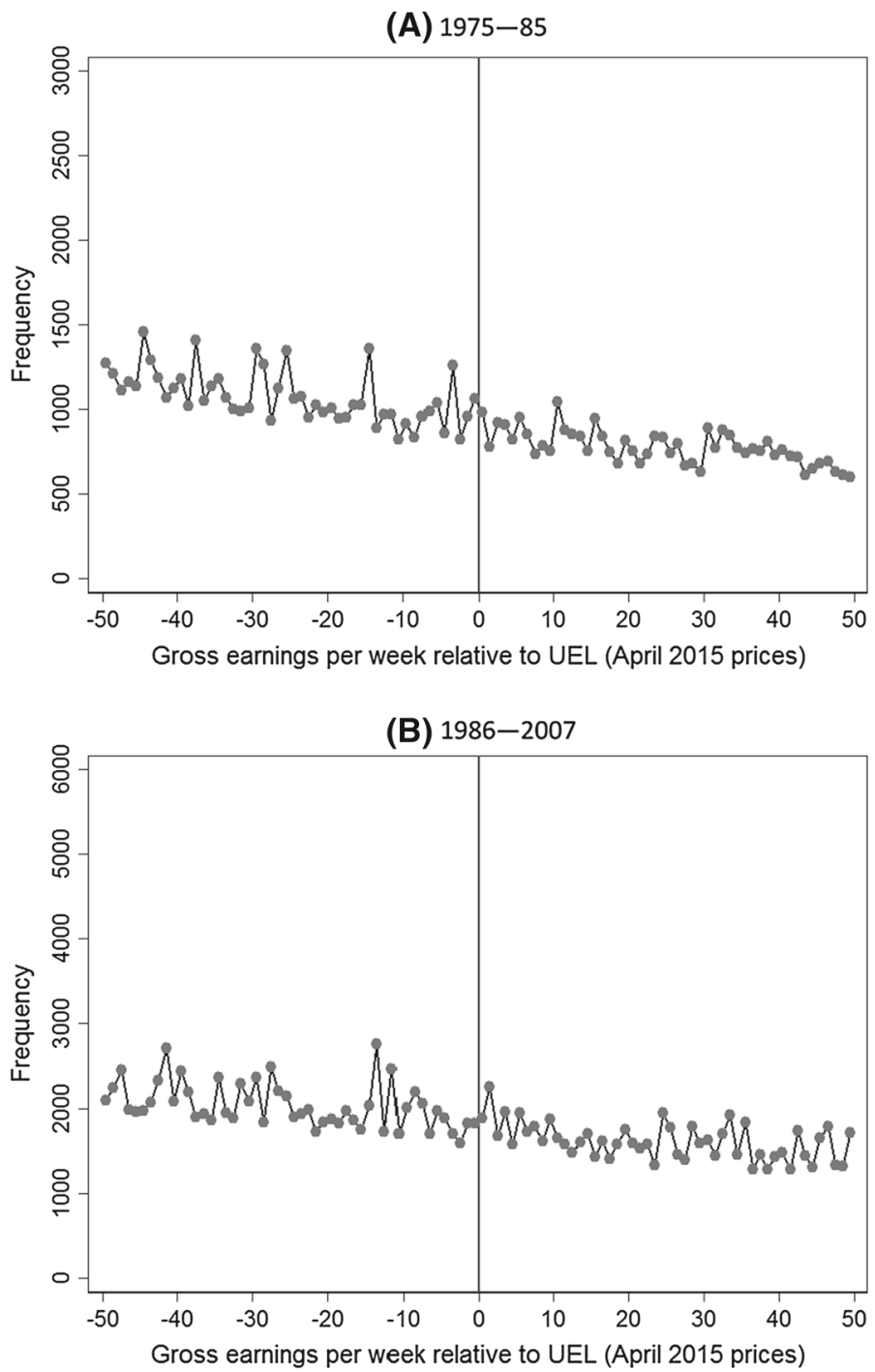

Fig. 1 Distribution of earnings around the Upper Earnings Limit Note figure shows the number of individuals in $£ 1$ bins of real earnings relative to the UEL Source authors' calculations using the New Earnings Survey Panel Dataset

In this volume, Alvaredo et al. (2017) argue that in the simplest, 'standard' static model of labour supply and demand, the incidence of the fall in marginal NICs rate at the threshold should be determined solely by the relative elasticities of supply and

Footnote 11 continued

alone. In effect, the 'true' kink is not as large, and thus less of a dip should be expected with any given elasticity. 
demand for labour around this threshold. They propose an approach to investigating this incidence which exploits the fact that labour cost, net earnings and gross earnings cannot all be smooth around a kink point in the tax schedule, since the extent to which the tax mechanically compresses the distribution of net earnings relative to the distribution of labour cost is different either side of the kink. The presence of a dip in the distribution of gross earnings at a ceiling, arising from behavioural responses to the different tax rates above and below, may serve to obscure such a discontinuity. As none is observable, we can continue by applying this approach to the UEL.

Under certain conditions (labour supply perfectly inelastic, labour demand perfectly elastic, and workers perfectly substitutable) we might expect the fall in the NICs rate at the UEL to be fully incident on the worker and hence (if workers' productivities are smoothly distributed) the density of labour cost to be smooth and continuous around the UEL. Likewise, under certain conditions (labour supply perfectly elastic, labour demand perfectly inelastic, and preferences smoothly distributed) we might expect full incidence on the employer and a smooth distribution of net earnings. In contrast, since gross earnings - after employer NICs, but before income tax and employee NICs-enters neither the individual's nor the firm's optimisation problem, in a simple economic model there is little reason to expect its distribution to be smooth and continuous around the UEL-that is, for the economic incidence of the fall in NICs rates to match the statutory incidence-except if by chance the relative elasticities of supply and demand for labour around the threshold coincide with the relative sizes of the kinks in the employee and employer NICs schedules.

When both employee and employer NICs rates change at the UEL (as from 1975 to 1985), at least two of these three earnings measures must (mechanically) exhibit a step-change in density at the UEL. When only the employee NICs rate changes at the UEL (as from 1985 to 2007), the densities of gross earnings and employer cost will move in tandem while the density of net earnings must (mechanically) move differently.

Alvaredo et al. propose testing for step-changes in these distributions by fitting a polynomial to the midpoints of gross earnings bins, including a dummy in the regression for whether the bin is above or below the cap, and testing the null hypothesis that the coefficient on the dummy is zero. Failure to reject this hypothesis implies failure to reject that the distribution of gross earnings is smooth and continuous around the UEL. They argue that given the absence of a dip at the UEL, this can only be consistent with the 'standard' model if statutory and economic incidence happen to coincide; that is, if the relative elasticities of labour supply and labour demand happen to be the same as the relative rates of employer and employee NICs.

Since the distributions of labour cost and net earnings are simple mechanical transformations of the distribution of gross earnings, based on the relevant tax rates, we can also use the same test to assess whether those distributions are smooth. It is trivial to calculate what discontinuity in the gross earnings distribution would be implied by a smooth distribution of labour cost or net earnings, so we can see whether those discontinuities are within the confidence interval for our coefficient of interest.

As a variant on our preferred approach, we also test for a discontinuity at the UEL using an estimator developed by McCrary (2008) (originally intended to check the validity of the 'no manipulation' assumption underlying regression discontinuity 
design studies). This extends the local linear density estimator of Cheng et al. (1997), and is implemented as a Wald test of the null hypothesis that the density of a variable is discontinuous at a point. However, this estimator is not entirely suitable for our purposes as it only tests for a discontinuity locally at the threshold (i.e. epsilon above versus epsilon below), rather than a sustained step-change in density from one side of the threshold to the other as we would expect from the mechanical effect of compressing the whole earnings distribution on one side of the threshold more than the other. The latter is what the polynomial method directly tests for. ${ }^{12}$

Our preferred polynomial specification is a quadratic, since the distribution displays only slight curvature, fitted to the distribution of weekly-ised real earnings in a window $£ 100$ (in April 2015 prices) either side of the UEL and run on data pooled across years to maximise sample size. This is shown in Fig. 2 for the two periods we analyse, 1975-1985 and 1986-2007.

The first two columns of Table 2 show the corresponding estimated discontinuities in gross earnings at the UEL - that is, the estimated coefficient on a dummy for being above the UEL - along with its standard error and $95 \%$ confidence interval. The estimates are not statistically significantly different from zero for either the period 1975-1985 (when employee and employer contributions are capped at the UEL) and for the period 1986-2007 (when only employee contributions were capped): that is, we cannot reject the null hypothesis that the distribution of gross earnings is smooth around the cap, and that the incidence of NICs is borne along statutory lines. This null hypothesis would imply that the effective incidence of the change in marginal rate matched the statutory incidence.

That has somewhat different implications in the two periods: in 1975-1985, it would imply employees bearing somewhat under half of the incidence of the NICs change (since the employee NICs rate fell at the UEL by less than the employer NICs rate did) whereas in the 1985-2007 period it would imply employees bearing all of the incidence (since the employer NICs rate did not change at the UEL during that period). ${ }^{13}$

As shown in the appendix, this finding is robust to the choice of polynomial order (Table 3), bin size (Table 4), and estimation window (Table 5). Given the proximity of our earnings data to the turn of the fiscal year (discussed in Sect. 3) we also perform the same exercise using the previous year's UEL, which gives similar results (Tables 6 , 7, 8, 9; Fig. 4).

As noted above, the same estimates can also be used to test the hypotheses that the distributions of labour cost and of net earnings are smooth. For the period 1975-

\footnotetext{
12 The fact that the McCrary test focuses exclusively on the discontinuity exactly at the threshold may also mean that it is more vulnerable to mismeasurement of the earnings variable, such as the possible omission of some benefits in kind noted in Sect. 3.

13 When interpreting the shares of effective incidence implied by the smoothness of gross earnings, recall that (as described in Sect. 3) additional earnings below, but not above, the UEL generated extra SERPS or State Second Pension entitlement for much the period we analyse. We should therefore think of the 'true' kink in the employee NICs schedule being somewhat smaller than shown in Table 1, since a (small) part of the employee NICs rate below the UEL is not a conventional tax but a form of retirement saving. If gross earnings is smooth, the share of the 'true' tax wedge borne by employees is slightly lower than their share of the headline tax wedge shown in Table 1.
} 


\section{(A) $1975-85$}

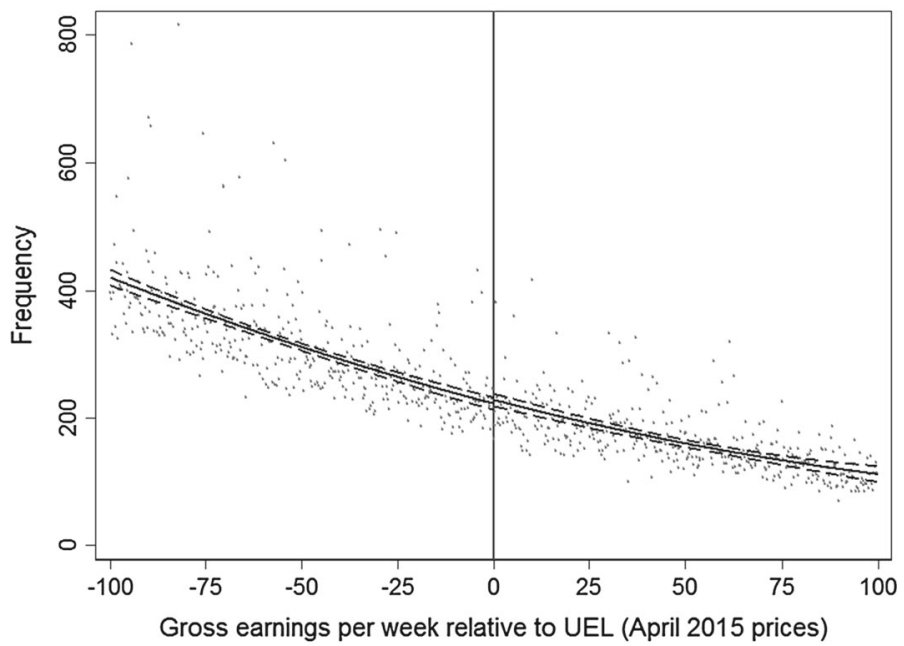

(B) $1986-2007$

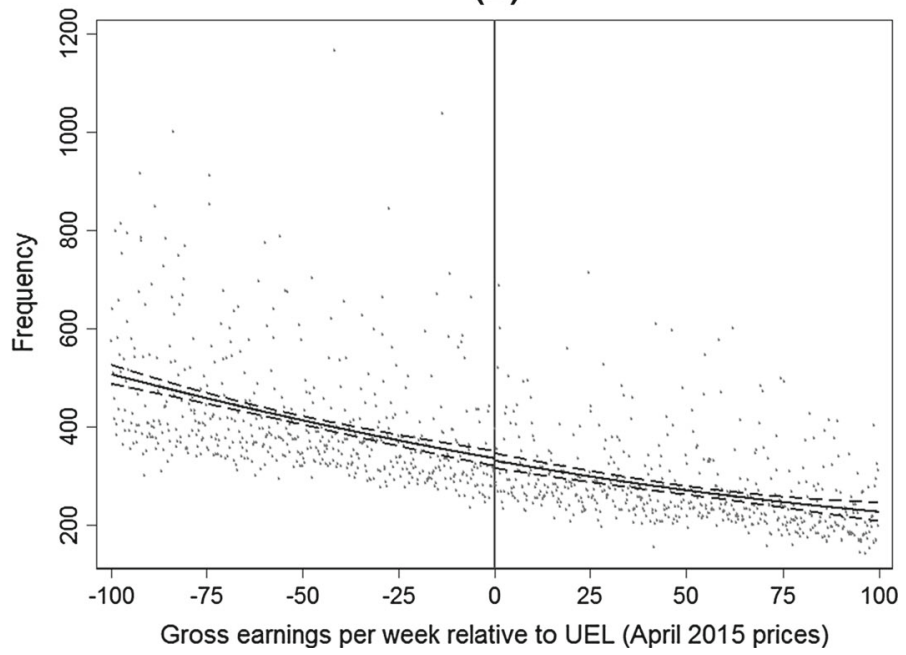

Fig. 2 Estimated discontinuity from preferred polynomial specification

Note figure shows the number of individuals in bins of real earnings relative to the UEL, overlaid with the predicted density obtained from fitting a quadratic curve to the midpoint of each bin Source authors' calculations using the New Earnings Survey Panel Dataset

1985, the mean marginal rate of employer NICs implies that a smooth distribution of labour cost would translate into a discontinuity in gross earnings of $-0.115 ;{ }^{14}$ this is outside the confidence interval for our estimate, so in our preferred specification we can

\footnotetext{
14 Alvaredo et al. (2017) show that, if labour cost is smooth, gross earnings must (mechanically) exhibit a change in density at the cap that is equal to $-\frac{\tau_{r}}{1+\tau_{r}}$, where $\tau_{r}$ is the rate of employer NICs levied below the UEL ( $10.35 \%$ on average over this period).
} 
Table 2 Estimated discontinuity in gross earnings at the UEL, pooled data

\begin{tabular}{|c|c|c|c|c|}
\hline & \multicolumn{2}{|l|}{ Polynomial } & \multicolumn{2}{|l|}{ McCrary } \\
\hline & $\begin{array}{l}(1) \\
1975-1985\end{array}$ & $\begin{array}{l}(2) \\
1986-2007\end{array}$ & $\begin{array}{l}(3) \\
1975-1985\end{array}$ & $\begin{array}{l}(4) \\
1986-2007\end{array}$ \\
\hline Estimate & 0.027 & -0.014 & -0.026 & 0.028 \\
\hline S.E. & $(0.036)$ & $(0.037)$ & $(0.014)$ & $(0.012)$ \\
\hline $95 \%$ C.I. & $-0.044,0.097$ & $-0.086,0.059$ & $-0.054,0.001$ & $0.005,0.051$ \\
\hline Bin size (£pw) & $£ 0.253$ & $£ 0.188$ & $£ 0.253$ & $£ 0.188$ \\
\hline Bandwidth (£pw) & - & - & $£ 54.379$ & $£ 39.787$ \\
\hline
\end{tabular}

Source authors' calculations using data from the New Earnings Survey Panel Dataset

reject the hypothesis that labour cost is smooth and incidence fully on the employee. But a smooth distribution of net earnings would (given employee NICs rates) imply discontinuity in gross earnings of +0.093 , which we cannot reject. For the period 1986-2007 we can only test whether the distribution of net earnings is smooth (as there is no downwards kink in the employer NICs schedule). This would imply a discontinuity in gross earnings of +0.093 , which this time is outside the confidence interval for our estimate. The rejection or otherwise of the hypotheses of smooth labour cost or net earnings is less robust to the sensitivity tests shown in the appendix, sometimes falling inside and sometimes outside the relevant confidence intervals. However, these are tests of relatively extreme hypotheses - that incidence is entirely on one side of the market. The broader message we take from these exercises is that our standard errors, and the fluctuations in estimates between different specifications, are quite large relative to the effects we are trying to distinguish. In other words, we do not have great statistical power: even if we reject the hypothesis that the economic incidence is entirely on one side of the market, our estimates still leave open a wide range of possible incidence shares: we cannot reject the hypothesis that economic incidence follows statutory incidence, but nor do we identify them as precisely aligned.

The third and fourth columns of Table 2 show the results from the McCrary tests. The confidence intervals overlap with those from the polynomial estimator but are much narrower. The hypothesis that gross earnings are smooth is rejected for 1985-2007 and not rejected for 1975-1986, but both results are borderline. The results suggest that, if anything, there is a statistically significant positive discontinuity at the UEL in 19861975 , consistent with some shifting of employee NICs onto employers. However, this estimate is not robust to the choice of bandwidth or estimation window. ${ }^{15}$ Moreover, as Fig. $5 \mathrm{~b}$ in the appendix shows, the discontinuity detected by the McCrary test in Table 2 does not appear to be the step-change in density at the threshold predicted by theory. Rather, the test detects a small jump in the density of gross earnings just above the threshold, which quickly reverts to its level below. ${ }^{16}$ This is the downside

\footnotetext{
15 These sensitivity results are available from the authors on request.

16 The pattern in fact resembles what would be expected if people moved from below the UEL to bunch above the UEL, as if there were a notch rather than a kink at the UEL; but since there is no such notch, it would be hard to rationalise such behaviour, and indeed looking at the earnings distribution in Fig. 1 it
} 


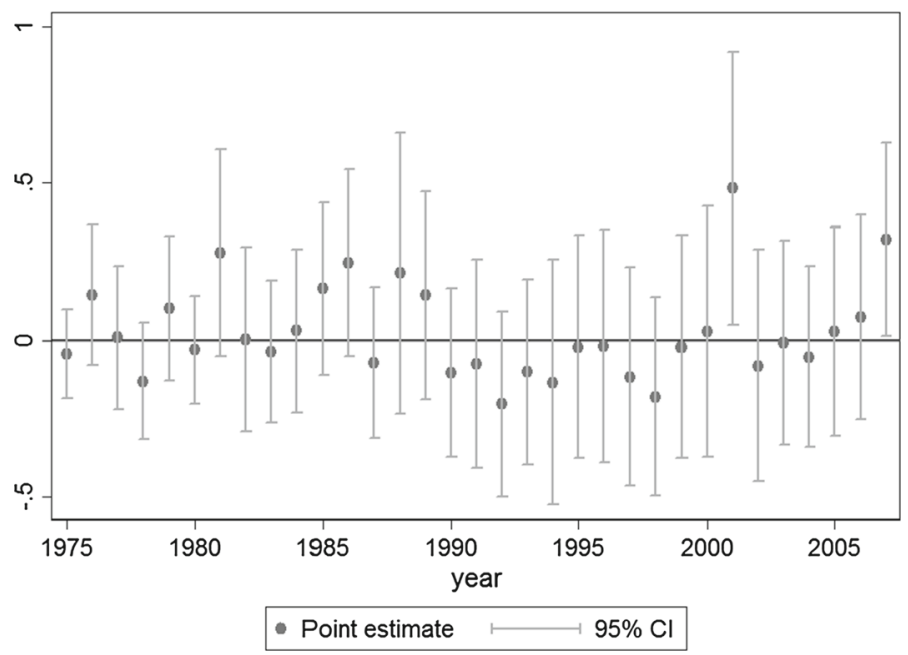

Fig. 3 Discontinuity estimates, annual data

Note figure shows the estimated discontinuity (and its associated 95\% confidence interval) obtained from fitting a quadratic curve to the distribution of real weekly gross earnings around the Upper Earnings Limit, as described in the text

Source authors' calculations using the New Earnings Survey Panel Dataset

we noted above of testing for a discontinuity precisely at the notch when we are really interested in whether there is a sustained step-change. As a result, we consider the polynomial-derived estimate (of a smooth distribution of gross earnings around the threshold) more credible.

Finally, we apply our approach to each year's data separately. But the much smaller sample sizes result in polynomial estimates that are statistically insignificant for all but 1 year (2001), with extremely wide confidence intervals, as shown by Fig. 3. ${ }^{17}$ Although the McCrary tests yield some statistically significant discontinuity estimates, there appears to be no systematic pattern, with some years yielding positive estimates and others negative (see Table 10 in the appendix). Again, when plotted, those estimates which are significant look more like local spikes in density than the discontinuous stepchange we would expect were the distributions of labour cost or net earnings smooth.

\section{Conclusion}

Simple economic theory suggests there should be a dip in the earnings distribution around thresholds where the marginal tax rate falls, with the size of the dip reflecting the elasticity of taxable earnings in the vicinity of the threshold. Over a 32-year period in the UK we cannot detect such a dip at the Upper Earnings Limit of the UK's social

\section{Footnote 16 continued}

would be hard to conclude that there is clear bunching above the threshold and a dip below it - the statistical result may be a consequence of the particular way the local linear density estimator operates.

17 Table 10 contains the full set of annual point estimates and standard errors underlying Fig. 3. 
security contribution schedule, despite a large fall in the marginal contribution rate at the UEL (more than $20 \%$ points for much of the period). This implies the earnings of those near these contribution ceilings are unresponsive to the change in SSC rates, either because the underlying elasticities are very low or because optimisation frictions (whether informational, institutional or driven by adjustment costs) are significant. This is consistent with the widespread (though not universal) finding in the literature of little bunching in earnings from employment at thresholds where the marginal rate rises (see Kleven 2016, for a survey).

Given this lack of behavioural response, Alvaredo et al. (this volume) show that the smoothness or otherwise of the densities of labour cost, gross earnings and net earnings around the threshold can be informative about the incidence of SSCs for those near the threshold. This is because a fall in the marginal tax rate mechanically compresses the relative distributions either side of the threshold, meaning the three densities cannot all be smooth around a kink in the tax schedule. There will be an upward step-change in the density of labour cost insofar as the change in the marginal NICs rate is incident on employers, and a downward step-change in the density of net earnings insofar as it is incident on employees.

With our preferred specification, we cannot reject the hypothesis that the density of gross earnings is smooth around the UEL. This finding is robust to the specification of the polynomial, and may reflect a substantive role for statutory incidence in determining economic incidence. ${ }^{18}$ However, while we can reject the hypotheses that the economic incidence of NICs is borne entirely by employees (for the period 19751985) or employers (for the period 1986-2007) under most specifications, a lack of power means our results are also consistent with other less extreme incidence shares. As a result, we are wary of drawing strong conclusions from the evidence in this paper alone and advise readers to interpret our results in conjunction with the others in this volume and elsewhere.

Open Access This article is distributed under the terms of the Creative Commons Attribution 4.0 International License (http://creativecommons.org/licenses/by/4.0/), which permits unrestricted use, distribution, and reproduction in any medium, provided you give appropriate credit to the original author(s) and the source, provide a link to the Creative Commons license, and indicate if changes were made.

\section{Appendix}

See Tables 3, 4, 5, 6, 7, 8, 9 and 10 .

\footnotetext{
18 The alternative McCrary test does sometimes reject the hypothesis of smooth gross earnings, but we attach little weight to that, partly because it is sensitive to the precise specification and, more importantly, because it is less well suited to testing our hypothesis, since it is designed to capture a sharp discontinuity exactly at the threshold rather than a sustained step-change in the density either side.
} 
Table 3 Sensitivity of main estimates to order of polynomial

\begin{tabular}{|c|c|c|c|c|c|c|c|c|c|c|}
\hline \multirow{3}{*}{$\begin{array}{l}\text { Polynomial } \\
\text { order } \\
\text { Estimate }\end{array}$} & \multicolumn{5}{|c|}{ 1975-1985 } & \multicolumn{5}{|c|}{ 1986-2007 } \\
\hline & \multicolumn{2}{|l|}{ Main } & \multicolumn{3}{|c|}{ Sensitivity } & \multicolumn{2}{|l|}{ Main } & \multicolumn{3}{|c|}{ Sensitivity } \\
\hline & 0.027 & -0.015 & -0.015 & -0.026 & -0.015 & -0.014 & -0.052 & -0.051 & -0.011 & 0.024 \\
\hline S.E. & 0.036 & 0.047 & 0.047 & 0.057 & 0.065 & 0.037 & 0.048 & 0.048 & 0.059 & 0.068 \\
\hline $95 \%$ CI- & -0.044 & -0.107 & -0.108 & -0.138 & -0.143 & -0.086 & -0.146 & -0.145 & -0.127 & -0.110 \\
\hline $95 \% \mathrm{CI}+$ & 0.097 & 0.077 & 0.078 & 0.085 & 0.113 & 0.059 & 0.043 & 0.043 & 0.105 & 0.158 \\
\hline $\begin{array}{l}\text { Polynomial } \\
\text { order }\end{array}$ & $2 n d$ & $3 r d$ & 4 th & 6 th & 8 th & 2 nd & $3 \mathrm{rd}$ & 4th & 6 th & 8 th \\
\hline
\end{tabular}

Source authors' calculations using data from the New Earnings Survey Panel Dataset

Table 4 Sensitivity of main estimates to bin size

\begin{tabular}{|c|c|c|c|c|c|c|c|c|}
\hline \multirow[b]{3}{*}{ Estimate } & \multicolumn{4}{|c|}{ 1975-1985 } & \multicolumn{4}{|c|}{ 1986-2007 } \\
\hline & \multicolumn{2}{|l|}{ Main } & \multicolumn{2}{|c|}{ Sensitivity } & \multicolumn{2}{|l|}{ Main } & \multicolumn{2}{|c|}{ Sensitivity } \\
\hline & 0.027 & 0.024 & 0.023 & 0.029 & -0.014 & -0.014 & -0.014 & -0.014 \\
\hline S.E. & 0.036 & 0.036 & 0.034 & 0.034 & 0.037 & 0.038 & 0.037 & 0.036 \\
\hline $95 \% \mathrm{CI}-$ & -0.044 & -0.045 & -0.044 & -0.039 & -0.086 & -0.087 & -0.086 & -0.085 \\
\hline $95 \% \mathrm{CI}+$ & 0.097 & 0.094 & 0.091 & 0.097 & 0.059 & 0.060 & 0.059 & 0.058 \\
\hline Bin size & $£ 0.253$ & $£ 0.127$ & $£ 0.507$ & $£ 1.267$ & $£ 0.188$ & $£ 0.094$ & $£ 0.376$ & $£ 0.940$ \\
\hline
\end{tabular}

Source authors' calculations using data from the New Earnings Survey Panel Dataset

Table 5 Sensitivity of main estimates to estimation window

\begin{tabular}{|c|c|c|c|c|c|c|}
\hline & \multicolumn{3}{|c|}{ 1975-1985 } & \multicolumn{3}{|c|}{ 1986-2007 } \\
\hline & Main & Sensitivit & & Main & Sensitivit & \\
\hline Estimate & 0.027 & -0.015 & 0.056 & -0.014 & -0.025 & -0.014 \\
\hline S.E. & 0.036 & 0.043 & 0.028 & 0.037 & 0.050 & 0.036 \\
\hline $95 \% \mathrm{CI}-$ & -0.044 & -0.100 & 0.001 & -0.086 & -0.123 & -0.085 \\
\hline $95 \% \mathrm{CI}+$ & 0.097 & 0.070 & 0.111 & 0.059 & 0.072 & 0.058 \\
\hline Window & $\pm £ 100$ & $\pm £ 50$ & $\pm £ 200$ & $\pm £ 100$ & $\pm £ 50$ & $\pm £ 200$ \\
\hline
\end{tabular}

Source authors' calculations using data from the New Earnings Survey Panel Dataset 
Table 6 Sensitivity of estimates using previous year's threshold to order of polynomial

\begin{tabular}{|c|c|c|c|c|c|c|c|c|c|c|}
\hline \multirow[t]{2}{*}{ Polynomial order } & \multicolumn{5}{|c|}{$1975-1985$} & \multicolumn{5}{|c|}{ 1986-2007 } \\
\hline & Main & & Sensitivi & & & Main & & Sensitivi & & \\
\hline Estimate & 0.002 & -0.009 & -0.009 & 0.010 & 0.042 & -0.016 & 0.008 & 0.008 & 0.033 & 0.071 \\
\hline S.E. & 0.032 & 0.043 & 0.043 & 0.052 & 0.060 & 0.034 & 0.046 & 0.046 & 0.055 & 0.064 \\
\hline $95 \%$ CI- & -0.061 & -0.093 & -0.093 & -0.092 & -0.076 & -0.083 & -0.082 & -0.082 & -0.075 & -0.053 \\
\hline $95 \% \mathrm{CI}+$ & 0.065 & 0.075 & 0.075 & 0.112 & 0.160 & 0.051 & 0.098 & 0.098 & 0.140 & 0.196 \\
\hline Polynomial order & 2nd & $3 \mathrm{rd}$ & 4 th & 6th & 8th & 2nd & $3 r d$ & 4 th & 6th & 8th \\
\hline
\end{tabular}

Source authors' calculations using data from the New Earnings Survey Panel Dataset

Table 7 Sensitivity of estimates using previous year's threshold to bin size

\begin{tabular}{|c|c|c|c|c|c|c|c|c|}
\hline \multirow[b]{3}{*}{ Estimate } & \multicolumn{4}{|c|}{ 1975-1985 } & \multicolumn{4}{|c|}{ 1986-2007 } \\
\hline & \multicolumn{2}{|l|}{ Main } & \multicolumn{2}{|c|}{ Sensitivity } & \multicolumn{2}{|l|}{ Main } & \multicolumn{2}{|c|}{ Sensitivity } \\
\hline & 0.002 & -0.003 & -0.001 & 0.016 & -0.016 & -0.018 & -0.014 & -0.014 \\
\hline S.E. & 0.032 & 0.032 & 0.032 & 0.035 & 0.034 & 0.035 & 0.035 & 0.033 \\
\hline $95 \% \mathrm{CI}-$ & -0.061 & -0.066 & -0.063 & -0.053 & -0.083 & -0.086 & -0.083 & -0.078 \\
\hline $95 \% \mathrm{CI}+$ & 0.065 & 0.060 & 0.062 & 0.085 & 0.051 & 0.049 & 0.055 & 0.051 \\
\hline Bin size & $£ 0.212$ & $£ 0.106$ & $£ 0.423$ & $£ 1.058$ & $£ 0.176$ & $£ 0.088$ & $£ 0.351$ & $£ 0.878$ \\
\hline
\end{tabular}

Source authors' calculations using data from the New Earnings Survey Panel Dataset

Table 8 Sensitivity of estimates using previous year's threshold to estimation window

\begin{tabular}{|c|c|c|c|c|c|c|}
\hline \multirow[b]{3}{*}{ Estimate } & \multicolumn{3}{|c|}{ 1975-1985 } & \multicolumn{3}{|c|}{ 1986-2007 } \\
\hline & \multirow{2}{*}{$\frac{\text { Main }}{0.002}$} & \multicolumn{2}{|c|}{ Sensitivity } & \multirow{2}{*}{$\begin{array}{l}\text { Main } \\
-0.016\end{array}$} & \multicolumn{2}{|c|}{ Sensitivity } \\
\hline & & 0.005 & -0.081 & & 0.026 & -0.044 \\
\hline S.E. & 0.032 & 0.042 & 0.022 & 0.034 & 0.049 & 0.023 \\
\hline $95 \%$ CI- & -0.061 & -0.078 & -0.123 & -0.083 & -0.070 & -0.088 \\
\hline $95 \% \mathrm{CI}+$ & 0.065 & 0.088 & -0.038 & 0.051 & 0.123 & 0.001 \\
\hline Window & $\pm £ 100$ & $\pm £ 50$ & $\pm £ 200$ & $\pm £ 100$ & $\pm £ 50$ & $\pm £ 200$ \\
\hline
\end{tabular}

Source authors' calculations using data from the New Earnings Survey Panel Dataset 
Table 9 Estimated discontinuity from 2nd order polynomial, annual data

\begin{tabular}{|c|c|c|c|c|c|c|}
\hline Year & $\mathrm{N}$ & Bin size & Estimate & S.E. & $\mathrm{CI}-$ & $\mathrm{CI}+$ \\
\hline 1975 & 31,947 & $£ 0.613$ & -0.043 & 0.072 & -0.185 & 0.098 \\
\hline 1976 & 19,115 & $£ 0.799$ & 0.143 & 0.114 & -0.079 & 0.366 \\
\hline 1977 & 20,279 & $£ 0.762$ & 0.008 & 0.117 & -0.221 & 0.237 \\
\hline 1978 & 17,944 & $£ 0.812$ & -0.131 & 0.094 & -0.316 & 0.054 \\
\hline 1979 & 18,518 & $£ 0.815$ & 0.101 & 0.118 & -0.130 & 0.331 \\
\hline 1980 & 17,444 & $£ 0.824$ & -0.031 & 0.087 & -0.202 & 0.140 \\
\hline 1981 & 12,963 & $£ 0.968$ & 0.278 & 0.168 & -0.052 & 0.607 \\
\hline 1982 & 12,671 & $£ 0.985$ & 0.002 & 0.151 & -0.293 & 0.297 \\
\hline 1983 & 12,334 & $£ 0.995$ & -0.038 & 0.116 & -0.265 & 0.188 \\
\hline 1984 & 12,436 & $£ 0.997$ & 0.029 & 0.133 & -0.233 & 0.290 \\
\hline 1985 & 12,994 & $£ 0.985$ & 0.164 & 0.140 & -0.110 & 0.439 \\
\hline 1986 & 12,703 & $£ 0.990$ & 0.246 & 0.152 & -0.053 & 0.544 \\
\hline 1987 & 14,161 & $£ 0.938$ & -0.073 & 0.123 & -0.315 & 0.169 \\
\hline 1988 & 17,851 & $£ 0.861$ & 0.213 & 0.228 & -0.234 & 0.660 \\
\hline 1989 & 19,040 & $£ 0.816$ & 0.143 & 0.169 & -0.188 & 0.474 \\
\hline 1990 & 20,952 & $£ 0.785$ & -0.103 & 0.138 & -0.373 & 0.166 \\
\hline 1991 & 18,479 & $£ 0.836$ & -0.076 & 0.171 & -0.410 & 0.259 \\
\hline 1992 & 18,671 & $£ 0.821$ & -0.205 & 0.151 & -0.501 & 0.091 \\
\hline 1993 & 17,347 & $£ 0.858$ & -0.102 & 0.151 & -0.397 & 0.193 \\
\hline 1994 & 17,907 & $£ 0.862$ & -0.135 & 0.200 & -0.528 & 0.258 \\
\hline 1995 & 18,264 & $£ 0.842$ & -0.021 & 0.182 & -0.378 & 0.335 \\
\hline 1996 & 17,646 & $£ 0.861$ & -0.019 & 0.190 & -0.392 & 0.353 \\
\hline 1997 & 17,389 & $£ 0.862$ & -0.118 & 0.178 & -0.467 & 0.231 \\
\hline 1998 & 18,113 & $£ 0.860$ & -0.181 & 0.162 & -0.498 & 0.137 \\
\hline 1999 & 17,617 & $£ 0.849$ & -0.022 & 0.182 & -0.379 & 0.335 \\
\hline 2000 & 15,557 & $£ 0.915$ & 0.026 & 0.204 & -0.375 & 0.426 \\
\hline 2001 & 13,729 & $£ 0.964$ & 0.483 & 0.223 & 0.046 & 0.920 \\
\hline 2002 & 14,523 & $£ 0.941$ & -0.083 & 0.189 & -0.453 & 0.288 \\
\hline 2003 & 15,255 & $£ 0.909$ & -0.009 & 0.167 & -0.336 & 0.318 \\
\hline 2004 & 15,418 & $£ 0.912$ & -0.053 & 0.147 & -0.342 & 0.235 \\
\hline 2005 & 15,769 & $£ 0.921$ & 0.027 & 0.170 & -0.306 & 0.360 \\
\hline 2006 & 16,406 & $£ 0.899$ & 0.072 & 0.166 & -0.253 & 0.397 \\
\hline 2007 & 13,173 & $£ 0.988$ & 0.319 & 0.157 & 0.011 & 0.627 \\
\hline
\end{tabular}

Source authors' calculations using data from the New Earnings Survey Panel Dataset 
Table 10 Estimated discontinuity from McCrary Test, annual data

\begin{tabular}{|c|c|c|c|c|c|c|c|}
\hline Year & $\mathrm{N}$ & Bin size & Bandwidth & Estimate & SE & C.I. - & C.I.+ \\
\hline 1975 & 31,947 & $£ 0.613$ & $£ 44.646$ & -0.110 & 0.037 & -0.183 & -0.038 \\
\hline 1976 & 19,115 & $£ 0.799$ & $£ 54.386$ & 0.127 & 0.045 & 0.038 & 0.215 \\
\hline 1977 & 20,279 & $£ 0.762$ & $£ 49.544$ & -0.040 & 0.045 & -0.129 & 0.048 \\
\hline 1978 & 17,944 & $£ 0.812$ & $£ 32.323$ & -0.092 & 0.061 & -0.211 & 0.027 \\
\hline 1979 & 18,518 & $£ 0.815$ & $£ 45.780$ & 0.011 & 0.050 & -0.086 & 0.109 \\
\hline 1980 & 17,444 & $£ 0.824$ & $£ 45.854$ & -0.222 & 0.051 & -0.322 & -0.122 \\
\hline 1981 & 12,963 & $£ 0.968$ & $£ 44.454$ & 0.586 & 0.062 & 0.466 & 0.707 \\
\hline 1982 & 12,671 & $£ 0.985$ & $£ 54.446$ & -0.178 & 0.054 & -0.284 & -0.072 \\
\hline 1983 & 12,334 & $£ 0.995$ & $£ 50.294$ & -0.213 & 0.057 & -0.324 & -0.102 \\
\hline 1984 & 12,436 & $£ 0.997$ & $£ 41.400$ & -0.104 & 0.064 & -0.230 & 0.022 \\
\hline 1985 & 12,994 & $£ 0.985$ & $£ 41.895$ & 0.056 & 0.063 & -0.067 & 0.179 \\
\hline 1986 & 12,703 & $£ 0.990$ & $£ 53.289$ & 0.309 & 0.055 & 0.202 & 0.417 \\
\hline 1987 & 14,161 & $£ 0.938$ & $£ 33.942$ & -0.140 & 0.069 & -0.275 & -0.004 \\
\hline 1988 & 17,851 & $£ 0.861$ & $£ 48.961$ & 0.366 & 0.050 & 0.268 & 0.464 \\
\hline 1989 & 19,040 & $£ 0.816$ & $£ 36.233$ & 0.231 & 0.053 & 0.127 & 0.334 \\
\hline 1990 & 20,952 & $£ 0.785$ & $£ 50.690$ & -0.299 & 0.043 & -0.384 & -0.214 \\
\hline 1991 & 18,479 & $£ 0.836$ & $£ 59.754$ & -0.208 & 0.042 & -0.291 & -0.125 \\
\hline 1992 & 18,671 & $£ 0.821$ & $£ 52.146$ & -0.280 & 0.044 & -0.367 & -0.194 \\
\hline 1993 & 17,347 & $£ 0.858$ & $£ 70.701$ & 0.054 & 0.042 & -0.028 & 0.136 \\
\hline 1994 & 17,907 & $£ 0.862$ & $£ 75.225$ & -0.284 & 0.040 & -0.362 & -0.205 \\
\hline 1995 & 18,264 & $£ 0.842$ & $£ 49.815$ & -0.122 & 0.046 & -0.213 & -0.032 \\
\hline 1996 & 17,646 & $£ 0.861$ & $£ 63.463$ & -0.168 & 0.043 & -0.253 & -0.084 \\
\hline 1997 & 17,389 & $£ 0.862$ & $£ 51.647$ & -0.345 & 0.046 & -0.436 & -0.254 \\
\hline 1998 & 18,113 & $£ 0.860$ & $£ 39.696$ & -0.409 & 0.054 & -0.515 & -0.302 \\
\hline 1999 & 17,617 & $£ 0.849$ & $£ 52.354$ & 0.061 & 0.044 & -0.026 & 0.148 \\
\hline 2000 & 15,557 & $£ 0.915$ & $£ 45.043$ & 0.174 & 0.056 & 0.065 & 0.283 \\
\hline 2001 & 13,729 & $£ 0.964$ & $£ 36.048$ & 0.897 & 0.060 & 0.779 & 1.014 \\
\hline 2002 & 14,523 & $£ 0.941$ & $£ 49.989$ & -0.052 & 0.052 & -0.154 & 0.050 \\
\hline 2003 & 15,255 & $£ 0.909$ & $£ 46.272$ & 0.305 & 0.054 & 0.198 & 0.411 \\
\hline 2004 & 15,418 & $£ 0.912$ & $£ 52.156$ & 0.168 & 0.050 & 0.071 & 0.265 \\
\hline 2005 & 15,769 & $£ 0.921$ & $£ 55.235$ & 0.168 & 0.048 & 0.073 & 0.263 \\
\hline 2006 & 16,406 & $£ 0.899$ & $£ 49.191$ & -0.075 & 0.052 & -0.177 & 0.027 \\
\hline 2007 & 13,173 & $£ 0.988$ & $£ 41.565$ & 0.513 & 0.057 & 0.401 & 0.625 \\
\hline
\end{tabular}

Source authors' calculations using data from the New Earnings Survey Panel Dataset 
See Figs. 4, 5 and 6.

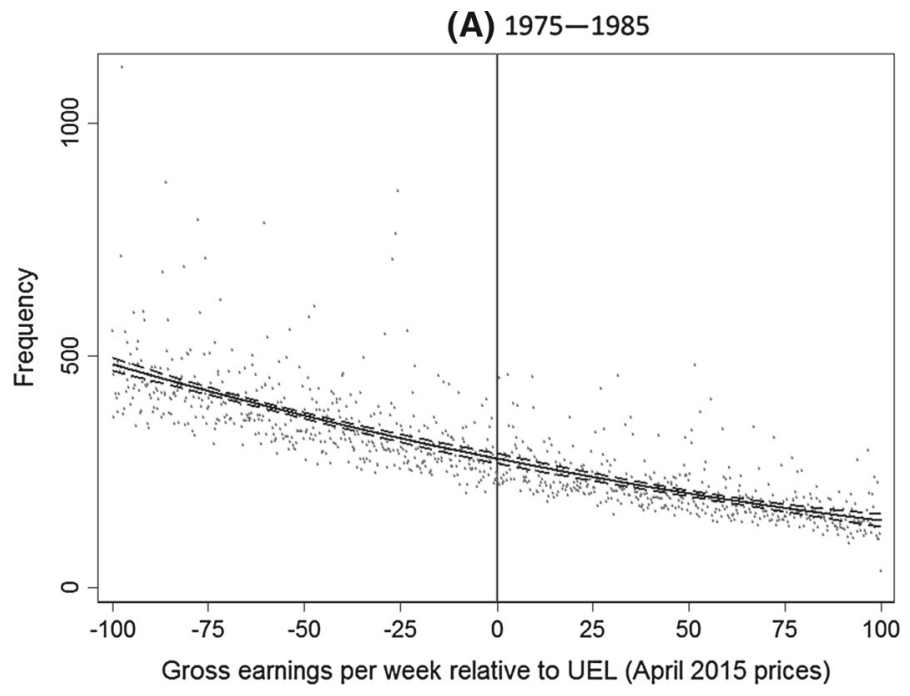

(B) $1986-2007$

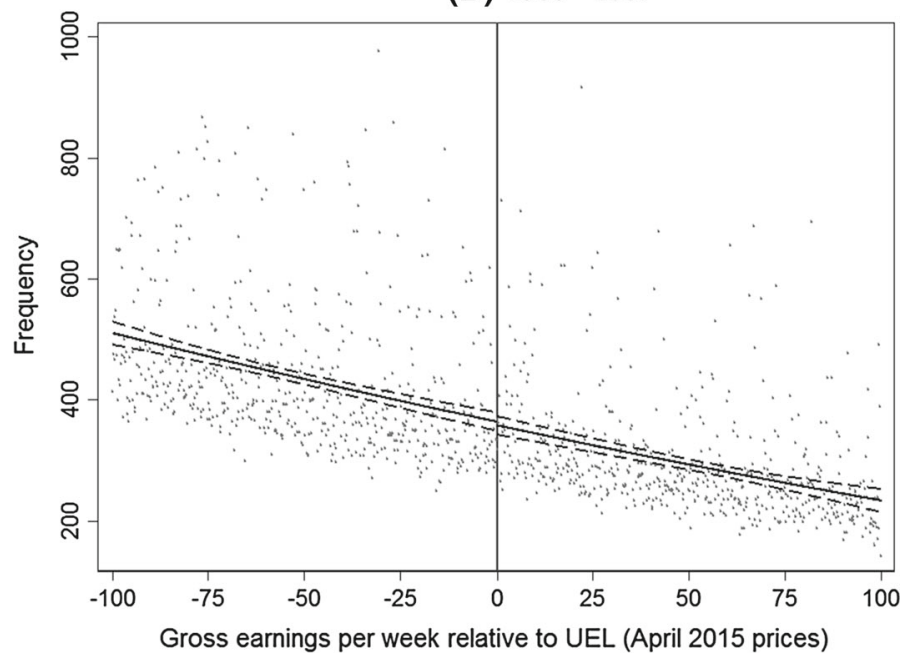

Fig. 4 Estimated discontinuity from preferred polynomial specification, previous year's threshold Note figure shows the number of individuals in bins of real earnings relative to the UEL, overlaid with the predicted density obtained from fitting a quadratic curve to the midpoint of each bin Source authors' calculations using the New Earnings Survey Panel Dataset 
(A) $1975-1985$

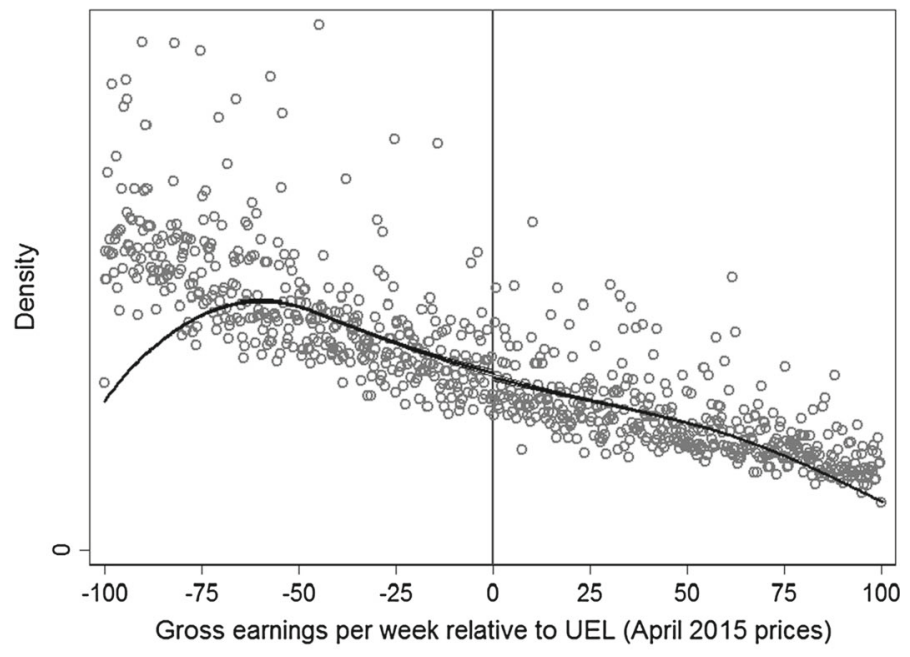

(B) 1986-2007

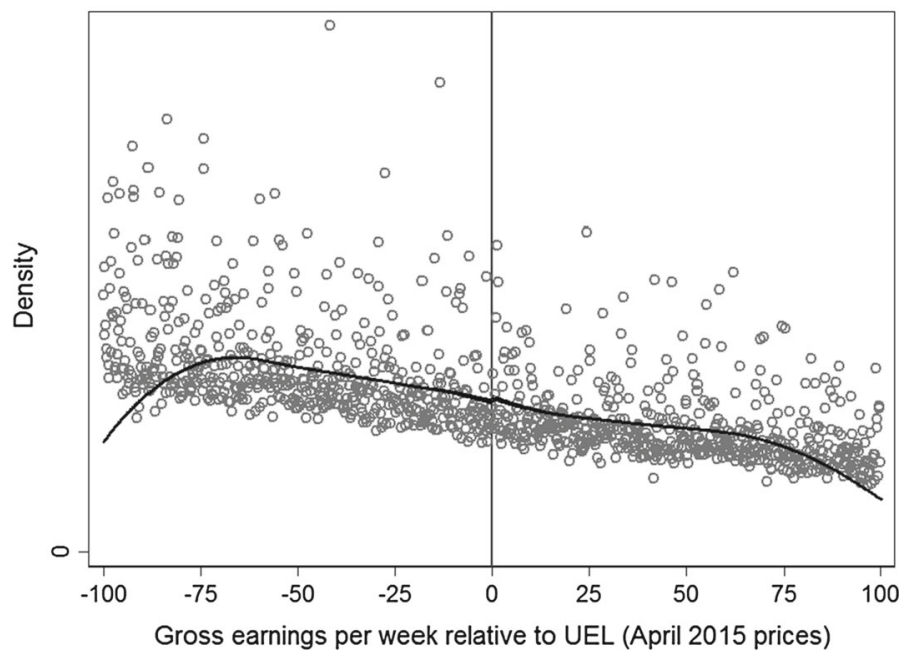

Fig. 5 Estimated discontinuity from McCrary test on pooled data, current year's threshold Note figure shows the number of individuals in bins of real earnings relative to the UEL, overlaid with the predicted density obtained from McCrary's (2008) estimator

Source authors' calculations using the New Earnings Survey Panel Dataset 

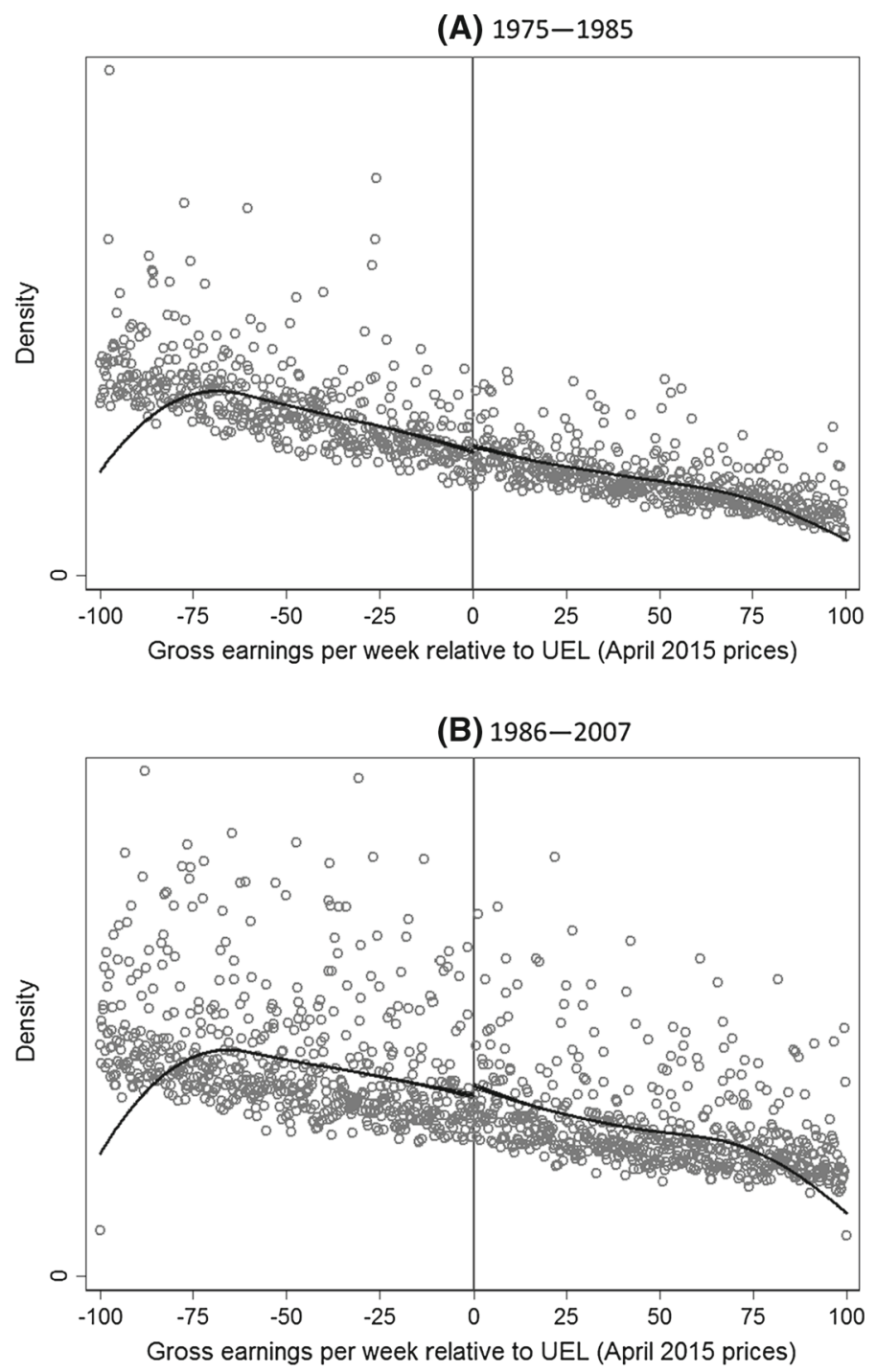

Fig. 6 Estimated discontinuity from McCrary test on pooled data, previous year's threshold

Note figure shows the number of individuals in bins of real earnings relative to the UEL, overlaid with the predicted density obtained from fitting a quadratic curve to the midpoint of each bin Source authors' calculations using the New Earnings Survey Panel Dataset

\section{References}

Adam, S., \& Loutzenhiser, G. (2007). Integrating income tax and national insurance: An interim report. W07/21. London: Institute for Fiscal Studies

Adam, S., Phillips, D., \& Roantree, B. (2017). 35 Years of reforms: A panel analysis of the incidence of, and employee and employer responses to, social security contributions in the UK. Mimeo. 
Alvaredo, F., Breda, T., Roantree, B., \& Saez, E. (2017). Contribution ceilings and the incidence of payroll taxes. De Economist. doi:10.1007/s10645-017-9294-7.

Cheng, M.-Y., Fan, J., \& Marron, J. S. (1997). On automatic boundary corrections. The Annals of Statistics, 25(4), 1691-1708.

Hood, A., \& Keiller, A. N. (2016). A survey of the GB benefit system. BN13. London: Institute for Fiscal Studies.

Hood, A., \& Oakley, L. (2014). The social security system: Long-term trends and recent changes. BN156. London: Institute for Fiscal Studies.

Kleven, H. J. (2016). Bunching. Annual Review of Economics, 8, 435-464.

Kleven, H. J., \& Waseem, M. (2013). Using notches to uncover optimization frictions and structural elasticities: Theory and evidence from Pakistan. The Quarterly Journal of Economics, 128(2), 669-723.

McCrary, J. (2008). Manipulation of the running variable in the regression discontinuity design: A density test. Journal of Econometrics, 142(2), 698-714.

Saez, E. (2010). Do taxpayers bunch at kink points? American Economic Journal: Economic Policy, 2(3), 180-212.

Summers, L. H. (1989). Some simple economics of mandated benefits. The American Economic Review, $79(2), 177-183$. 